\title{
Patients with non-alcoholic fatty liver disease may be a high-risk group for the development of colorectal polyps: A cross-sectional study
}

\author{
XIAOJUN YU* , LIN XIE* , YUFEN ZHOU, XIAOQIN YUAN, YUNLIN WU and PING CHEN \\ Department of Gastroenterology, Ruijin Hospital North, \\ Shanghai Jiaotong University School of Medicine, Shanghai 201801, P.R. China
}

Received June 29, 2020; Accepted September 28, 2020

DOI: $10.3892 /$ wasj.2020.71

\begin{abstract}
Non-alcoholic fatty liver disease (NAFLD) and colorectal polyps have been shown to have similar pathogenic factors. The understanding of the association between these two pathologies may contribute to the early diagnosis and treatment of colorectal tumors. The present study compared the biological characteristics of colorectal polyps between patients with and without NAFLD. For this purpose, 1,538 patients with colorectal polyps treated from July, 2013 and June, 2020 were included and divided into the NAFLD and control group (non-NAFLD group). The location, number, morphology, size and pathology of the polyps were compared between the 2 groups. For the analysis of the biological characteristics of the polyps, the multiple of number (74.5\%), percentages of polyps $>1.0 \mathrm{~cm}$ in diameter $(62 \%)$ and polyps with advanced adenomas. For the analysis of the biological characteristics of the polyps, the multiple of number $(74.5 \%)$, percentages of polyps in diameter of 1.0 to $<2.0 \mathrm{~cm}+\geq 2.0 \mathrm{~cm}$ (48.4 and $13.6 \%$, respectively) and polyps with advanced adenomas $(62.9 \%)$ in the NAFLD group exhibited significant differences compared with the control group $(69.5,39.2,6.3$ and $55.3 \%$, respectively; all $\mathrm{P}<0.05)$; however, no significant differences were observed in the location and morphology of the colorectal polyps between the patients with NAFLD and the controls $(\mathrm{P}>0.05)$. When the patients were stratified by sex, age and body mass index, it was found that the patients in the NAFLD group with a polyp size $<1.0 \mathrm{~cm}$ and those with advanced adenomas exhibited significant differences compared with the control group $(\mathrm{P}<0.05$, respectively). Further analysis revealed that the classification percentage of advanced
\end{abstract}

Correspondence to: Dr Ping Chen, Department of Gastroenterology, Ruijin Hospital North, Shanghai Jiaotong University School of Medicine, 999 Xiwang Road, Shanghai 201801, P.R. China

E-mail: chenping714@aliyun.com

${ }^{*}$ Contributed equally

Key words: non-alcoholic fatty liver disease, colorectal polyps, adenomas, biological characteristics, pathology adenomas in the NAFLD group only exhibited a statistically significant difference compared with the control group in patients with a lower weight $(\mathrm{P}<0.05)$. On the whole, the present study demonstrates that NAFLD is significantly associated with the presence of colorectal polyps, particularly in patients with multiple polyps, those with a large size and with villous features (advanced adenomas). Patients with NAFLD may thus be considered a target group for screening colonoscopy.

\section{Introduction}

Colorectal polyps have been considered precursors of hereditary and sporadic colorectal cancer. Currently, the incidence of colorectal polyps and colorectal cancer has been increasing over the recent decades worldwide. The identification of risk factors for colorectal cancer and performing colonoscopy are considered efficient surveillance programs for the detection of colorectal polyps and for the reduction of malignant progression and mortality among the general population (1).

Non-alcoholic fatty liver disease (NAFLD) is the most common cause of chronic liver disease. There is currently increasing evidence to indicate that NAFLD is a multisystem disease, affecting extra-hepatic organs. For example, NAFLD increases the risk of developing type 2 diabetes mellitus, cardiovascular (CVD) and cardiac diseases, and chronic kidney disease. Moreover, epidemiological research has found that the occurrence of NAFLD is associated with colorectal adenomas and advanced neoplasms (2). A previous study investigated 2,917 subjects, who had been divided into 2 groups (556 with adenomatous polyps and 2,361 who were polyp-free), and found that NAFLD was an independent risk factor for colorectal adenoma (3). However, that study did not examine the association between the location, number, morphology, size, pathological features and advanced adenomatous polyps and NAFLD.

In the present study, 1,538 cases of patients with colorectal polyps were retrospectively surveyed to compare the biological characteristics of colorectal polyps in patients with and without NAFLD. The association between NAFLD and features of colorectal polyps was also analyzed, so as to provide clinical evidence for the guidance of colorectal polyp screening in patients with NAFLD. 


\section{Patients and methods}

Study design. The present study is a cross-sectional retrospective study that was performed at the Department of Gastroenterology, Shanghai Ruijin Hospital North from July, 2013 and June, 2020. All the patients signed an informed consent form prior to the procedure. The informed consent forms obtained the consent of the patients to use their clinical data, and they were assured that no identifiable personal information would be disclosed. The present study was approved by the Clinical Trial Ethics Committee of Ruijin Hospital North, Shanghai Jiaotong University School of Medicine (Shanghai, China; approval no. 2017-2-01).

Patients. Abdominal ultrasonography was performed by professional radiologists to diagnose fatty liver. According to the 4 knowledgeable ultrasound criteria (liver brightness, deep attenuation, hepatorenal echo contrast and vascular blurring), subjects who met the hepatorenal contrast and liver brightness criteria were diagnosed with fatty liver disease. The inclusion and diagnosis of NAFLD were based on the clinical diagnostic criteria or the working definition of NAFLD in the Guidelines for the Diagnosis and Treatment of Non-Alcoholic Fatty Liver Disease (Revised in January, 2010) formulated by the Fatty Liver and Alcoholic Liver Disease Group of the Hepatology Branch of the Chinese Medical Association when fatty liver was present in the absence of the following: i) Viral hepatitis (hepatitis B or hepatitis C); ii) hepatic cirrhosis and liver carcinoma; iii) autoimmune liver disease or other liver disease; and iv) excess alcohol consumption (>140 g/week for males or $>70 \mathrm{~g} /$ week for females) (4).

All asymptomatic Chinese subjects were received screening colonoscopies at the large Endoscopy Center of Ruijin Hospital North were prospectively recruited in the present study. The inclusion criteria included the following: i) No symptoms of colorectal cancer, including rectal bleeding, anorexia, or changes in bowel habits over the past 4 weeks, or a weight loss of $>5 \mathrm{~kg}$ over the past 6 months; and ii) not having received any colorectal cancer-related colonoscopy screening tests over the past 5 years. The exclusion criteria were as follows: i) Long-term and heavy alcohol consumption, but with a B ultrasound examination which revealed negative results for fatty liver; ii) any other intestinal diseases; iii) the long-term use of aspirin or any other non-steroidal anti-inflammatory drugs (NSAIDs); iv) a history of any malignant tumors; v) a definite family history of gastrointestinal malignancy or familial adenomatous polyposis. The following factors were examined retrospectively: Age, sex, weight, height and body mass index (BMI). The (BMI) is calculated by dividing the person's weight in kilograms by the square of their height in meters, and is thus given in units of $\mathrm{kg} / \mathrm{m}^{2}$. The definition of obesity was based on a BMI $\geq 24 \mathrm{~kg} / \mathrm{m}^{2}$ in both sexes of the following China Diabetes Federation metabolic syndrome criteria (5).

The enrolled patients were divided into the NAFLD group and the control group (non-NAFLD group). A total of 1,538 cases of patients were enrolled in the present study, as presented in Table I.

Endoscopic procedure. Routine bowel preparation procedures with a total of 3 liters of polyethylene glycol lavage solution in split dosing were performed. A colonoscopy examination was performed by experienced gastroenterologists at Ruijin Hospital North. The completed colonoscopy examination was defined as cecal intubation with photographic evidence of the cecum using endoscopes (Fujinon VP-4450HD-EG-590WM; Fujifilm) equipped with a Picture Archiving and Communication System (PacsVideo diagnostic work station, Neusoft Group Co., Ltd.). The size, morphology and number of polyps were estimated by gastroenterologists. The gastroenterologists performing the colonoscopies were blinded to the study design. They defined the location of all lesions as distal (for lesions located in the rectum, sigmoid, or descending colon) and proximal (those located in the splenic flexure, transverse colon, hepatic flexure, ascending colon, or rectum). All polyp samples were sent for histological examination in an accredited laboratory. Histological specimens were reviewed by an experienced team of pathologists who were blinded to the colonoscopy reports and the study design throughout the study.

The pathological types of colorectal polyps were classified into adenomatous polyps, hyperplastic polyps, hamartomatous polyps and inflammatory polyps according to the World Health Organization histology reporting criteria (6). The latter three were classified as non-adenomatous polyps in the present study. The adenomatous polyps were divided into non-advanced adenomatous and advanced adenomatous polyps, and were defined as an adenoma sized at $\geq 10 \mathrm{~mm}$, any lesions with at least $25 \%$ villous components and adenomas with high-grade intraepithelial neoplasia. The biological characteristics of the multiple polyps were described by the individual with the largest diameter or the highest pathological grades; if the two were not the same polyp, the individual with the higher pathological grade was used.

Histological evaluation. The biopsy samples were fixed in $4 \%$ formalin, embedded in paraffin at room temperature, and were performed on $4-\mu \mathrm{m}$-thick sections. The histopathological changes of the specimens were examined by hematoxylin and eosin staining and were observed under a light microscope at x400 magnification (Olympus BX-51; Olympus Corporation). Histological diagnosis was independently performed by 2 experienced pathologists.

Statistical analysis. The SPSS 19.0 (IBM Corp.) statistical package for Windows was used for the statistical analysis. Data concerning age and BMI are expressed as the means \pm SD. Differences in age and BMI between the 2 groups were analyzed by the independent samples t-test. The Chi-square test was used to compare categorical variables between the different groups. All of the calculated P-values were two-tailed. $\mathrm{P}<0.05$ was considered to indicate a statistically significant difference.

\section{Results}

Characteristics of patients with and without NAFLD. A total of 1,538 cases of eligible patients with colorectal polyps, including 550 cases of NAFLD (NAFLD group), 988 cases without NAFLD (control group), were enrolled in the present study. No statistically significant differences were observed in sex and age between the 2 groups ( $\mathrm{P}>0.05)$. The BMI and body 
Table I. Characteristics of patients with and without NAFLD.

\begin{tabular}{|c|c|c|c|}
\hline Characteristic & NAFLD n=550 (\%) & Control n=988 (\%) & P-value \\
\hline Sex & & & 0.224 \\
\hline Male & $337(61.3)$ & $574(58.1)$ & \\
\hline Female & 213 (38.7) & $414(41.9)$ & \\
\hline Age (years) & $59.9 \pm 10.7$ & $60.1 \pm 11.6$ & 0.740 \\
\hline Young of age ( $<60$ years) & $231(42.0)$ & $412(41.7)$ & 0.909 \\
\hline Older age ( $\geq 60$ years) & $319(58.0)$ & $576(58.3)$ & \\
\hline BMI $\left(\mathrm{kg} / \mathrm{m}^{2}\right)$ & $25.7 \pm 2.9$ & $23.3 \pm 2.9$ & 0.001 \\
\hline Normal weight $\left(<24 \mathrm{~kg} / \mathrm{m}^{2}\right)$ & $165(30.0)$ & $592(59.9)$ & 0.001 \\
\hline Obese $\left(\geq 24 \mathrm{~kg} / \mathrm{m}^{2}\right)$ & $385(70.0)$ & $396(40.1)$ & \\
\hline
\end{tabular}

Table II. Comparison of location, number, morphology, size, pathological features and advanced adenomatous polyps between the NAFLD and control groups.

\begin{tabular}{|c|c|c|c|c|}
\hline Parameter & Total & NAFLD group, n (\%) & Control, n (\%) & P-value \\
\hline Location & & & & 0.618 \\
\hline Right colon & $167(10.9)$ & $56(10.2)$ & $111(11.2)$ & \\
\hline Left colon+ rectum & $933(60.6)$ & $330(60.0)$ & $603(61.1)$ & \\
\hline Right colon + left colon + rectum & $438(28.5)$ & $164(29.8)$ & $274(27.7)$ & \\
\hline Number & & & & 0.037 \\
\hline Single & $441(28.7)$ & $40(25.5)$ & $301(30.5)$ & \\
\hline Multiple & $1,097(71.3)$ & $410(74.5)$ & $687(69.5)$ & \\
\hline Morphology & & & & 0.680 \\
\hline Flat & $516(33.6)$ & $182(33.1)$ & $334(33.8)$ & \\
\hline Subpedunculated & $717(46.6)$ & $264(48.0)$ & $453(45.9)$ & \\
\hline Pedunculated & 305 (19.8) & 104 (18.9) & $305(19.8)$ & \\
\hline Size & & & & 0.001 \\
\hline$<0.5 \mathrm{~cm}$ & $120(7.8)$ & $29 \quad(5.3)$ & $91 \quad(9.2)$ & \\
\hline 0.5 to $<1.0 \mathrm{~cm}$ & $628(40.8)$ & $180(32.7)$ & $448(45.3)$ & \\
\hline 1.0 to $<2.0 \mathrm{~cm}$ & $653(42.5)$ & $266(48.4)$ & 387 (39.2) & \\
\hline$\geq 2.0 \mathrm{~cm}$ & 137 (8.9) & 75 (13.6) & $62(6.3)$ & \\
\hline Pathological features & & & & 0.001 \\
\hline Non-adenomas & $145 \quad(9.4)$ & $23(4.2)$ & $122(12.3)$ & \\
\hline Non-advanced adenomas & $501(32.6)$ & $181(32.9)$ & $320(32.4)$ & \\
\hline Advanced adenomas & $892(58.0)$ & $346(62.9)$ & $546(55.3)$ & \\
\hline Advanced adenomas & & & & 0.012 \\
\hline Size $\geq 1 \mathrm{~cm}$ & $594(66.6)$ & $239(69.1)$ & $355(65.0)$ & \\
\hline$>25 \%$ Villous components & $256(28.7)$ & $84(24.3)$ & $172(31.5)$ & \\
\hline High-grade intraepithelial neoplasia & $42 \quad(4.7)$ & $23(6.6)$ & $19 \quad(3.5)$ & \\
\hline
\end{tabular}

weights of the patients in the NAFLD group were significantly higher than those of the control group, with the difference being statistically significant $(\mathrm{P}<0.05$; Table I).

Biological characteristics of polyps. No statistically significant differences were observed in the location of polyps between the NAFLD group and control group ( $P>0.05)$; however, the number of polyps in patients in the NAFLD group was higher than that in the control group $(\mathrm{P}<0.05)$. The morphology of the polyps was mainly that of subpedunculated polyps in the 2 groups $(\mathrm{P}>0.05)$. In the NAFLD group, the percentage of the size of polyps ranging from 1.0 to $2.0 \mathrm{~cm}$ was $48.4 \%$; moreover, the percentage of the size of polyps ranging from 0.5 to $1.0 \mathrm{~cm}$ was $45.3 \%$ in the control group, revealing statistically significant differences between the 2 groups $(\mathrm{P}<0.05$; Table II).

The pathological features of the polyps in both groups were mainly those of advanced adenomas; 
Table III. Comparison of features of polyps between the NAFLD and control groups according to sex.

\begin{tabular}{|c|c|c|c|c|c|c|}
\hline \multirow[b]{2}{*}{ Parameter } & \multicolumn{3}{|c|}{ Male } & \multicolumn{3}{|c|}{ Female } \\
\hline & $\begin{array}{l}\text { NAFLD } \\
(\mathrm{n}=337)\end{array}$ & $\begin{array}{l}\text { Control } \\
(\mathrm{n}=574)\end{array}$ & P-value & $\begin{array}{l}\text { NAFLD } \\
(\mathrm{n}=213)\end{array}$ & $\begin{array}{l}\text { Control } \\
(\mathrm{n}=414)\end{array}$ & P-value \\
\hline Location & & & 0.642 & & & 0.381 \\
\hline Right colon & $22(6.5)$ & $47 \quad(8.2)$ & & $34(15.9)$ & $64(15.4)$ & \\
\hline Left colon + rectum & $205(60.8)$ & $339(59.0)$ & & $125(58.7)$ & $264(63.8)$ & \\
\hline Right colon + left colon + rectum & $110(32.7)$ & $188(32.8)$ & & $54(25.4)$ & $86(20.8)$ & \\
\hline Number & & & 0.085 & & & 0.338 \\
\hline Single & $65(19.3)$ & $139(24.2)$ & & $75(35.2)$ & $162(39.1)$ & \\
\hline Multiple & $272(80.7)$ & $435(75.8)$ & & $138(64.8)$ & $252(60.9)$ & \\
\hline Morphology & & & 0.356 & & & 0.382 \\
\hline Flat & $92(27.3)$ & $180(31.3)$ & & $90(42.3)$ & $154(37.2)$ & \\
\hline Subpedunculated & $173(51.3)$ & $269(46.9)$ & & $91(42.7)$ & $184(44.4)$ & \\
\hline Pedunculated & $72(21.4)$ & $125(21.8)$ & & $32(15.0)$ & $76(18.4)$ & \\
\hline Size & & & 0.000 & & & 0.001 \\
\hline$<0.5 \mathrm{~cm}$ & $18(5.4)$ & $51(8.9)$ & & $11(5.2)$ & $40 \quad(9.7)$ & \\
\hline $0.5-<1.0 \mathrm{~cm}$ & $111(32.9)$ & $236(41.1)$ & & $69(32.4)$ & $212(51.2)$ & \\
\hline $1.0-<2.0 \mathrm{~cm}$ & $156(46.3)$ & $249(43.4)$ & & $110(51.6)$ & $138(33.3)$ & \\
\hline$\geq 2.0 \mathrm{~cm}$ & $52(15.4)$ & $38 \quad(6.6)$ & & $23(10.8)$ & $24 \quad(5.8)$ & \\
\hline Pathological features & & & 0.006 & & & 0.001 \\
\hline Non-adenomas & $16(4.8)$ & $63(11.0)$ & & $7(3.3)$ & $59(14.3)$ & \\
\hline Non-advanced adenomas & $112(33.2)$ & $178(31.0)$ & & $69(32.4)$ & $142(34.3)$ & \\
\hline Advanced adenoma & $209(62.0)$ & $333(58.0)$ & & $137(64.3)$ & $213(51.4)$ & \\
\hline Advanced adenomas & & & 0.126 & & & 0.082 \\
\hline Size $\geq 1 \mathrm{~cm}$ & $147(70.4)$ & $225(67.6)$ & & $92(67.2)$ & $130(61.0)$ & \\
\hline$>25 \%$ Villous components & $49(23.4)$ & $97(29.1)$ & & $35(25.5)$ & $75(35.2)$ & \\
\hline High-grade intraepithelial neoplasia & $13(6.2)$ & $11(3.3)$ & & $10(7.3)$ & $8(3.8)$ & \\
\hline
\end{tabular}

however, the proportion of advanced adenomas in the NAFLD group $(62.9 \%)$ was significantly higher than that in the control group (55.3\%); the proportion of non-adenomatous polyps $(4.2 \%)$ in the NAFLD group was lower than that in the control group (12.3\%), revealing a statistically significantly difference between the 2 groups $(\mathrm{P}<0.05$; Table II). According to the advanced adenoma definitions, in the 2 groups of patients, the sizes of the polyps were mainly $\geq 1 \mathrm{~cm}$; however, the percentage of high-grade intraepithelial neoplasia $(6.6 \%)$ in the NAFLD group was higher than that in the control group $(3.5 \%)$, revealing statistically significant differences $(\mathrm{P}<0.05$; Table II).

Stratification analysis of subgroups according to sex, age and BMI

Sex stratification. In male and female patients, the polyp distribution area, number or morphology exhibited no statistically significant differences between the NAFLD group and control group ( $\mathrm{P}>0.05$, respectively); however, a polyp size of $1.0-<2.0 \mathrm{~cm}$ and $\geq 2.0 \mathrm{~cm}$ or the percentage of advanced adenomas were significantly higher in the NAFLD group compared with the control group $(\mathrm{P}<0.05)$. Further statistical analysis revealed that the classification percentage of advanced adenomas did not exhibit any statistically significant differences between the NAFLD and the control group in the male and female patients ( $\mathrm{P}>0.05$, respectively; Table III).

Age stratification. In the stratification of young and elderly patients, the location, number and morphology of polyps exhibited no statistically significant differences between the NAFLD group and the control group ( $\mathrm{P}>0.05$, respectively); however, in the stratification of the young and elderly patients, the polyp size of $1.0-<2.0 \mathrm{~cm}$ and $\geq 2.0 \mathrm{~cm}$ and the number of advanced adenomatous polyps were significantly higher in the NAFLD group compared with the control group $(\mathrm{P}<0.05$, respectively). Further analysis revealed that the classification percentage of advanced adenomas did not exhibit a statistically significant difference between the NAFLD group and the control groups in the young and elderly patients $(\mathrm{P}>0.05$; Table IV).

BMI stratification. In the stratification of patients with normal weight and those who were obese (overweight), the location, number and morphology of the polyps exhibited no statistically significant differences between the NAFLD group and the controls ( $\mathrm{P}>0.05$, respectively); however, in this stratification of body weight, a polyp size of $1.0-<2.0 \mathrm{~cm}$ and $\geq 2.0 \mathrm{~cm}$ and the number of advanced adenomatous polyps were significantly higher in the NAFLD group compared with the control group $(\mathrm{P}<0.05$, respectively). Further analysis 
Table IV. Comparison of features of polyps between the NAFLD and control groups according to age.

\begin{tabular}{|c|c|c|c|c|c|c|}
\hline \multirow[b]{2}{*}{ Parameter } & \multicolumn{3}{|c|}{ Young $(<60$ years old $)$} & \multicolumn{3}{|c|}{ Elderly ( $\geq 60$ years old) } \\
\hline & $\begin{array}{l}\text { NAFLD } \\
(\mathrm{n}=231)\end{array}$ & $\begin{array}{l}\text { Control } \\
(\mathrm{n}=412)\end{array}$ & P-value & $\begin{array}{l}\text { NAFLD } \\
(\mathrm{n}=319)\end{array}$ & $\begin{array}{l}\text { Control } \\
(\mathrm{n}=576)\end{array}$ & P-value \\
\hline Location & & & 0.099 & & & 0.316 \\
\hline Right colon & 17 (7.4) & $53(12.9)$ & & $39(12.2)$ & $58(10.1)$ & \\
\hline Left colon + rectum & $161(69.7)$ & $269(65.3)$ & & $169(53.0)$ & $334(58.0)$ & \\
\hline Right colon + left colon + rectum & $53(22.9)$ & $90(21.8)$ & & $111(34.8)$ & $184(31.9)$ & \\
\hline Number of polyps & & & 0.294 & & & 0.062 \\
\hline Single & $67(29.0)$ & $136(33.0)$ & & $73(22.9)$ & $165(28.6)$ & \\
\hline Multiple & $164(71.0)$ & $276(67.0)$ & & $246(77.1)$ & $411(71.4)$ & \\
\hline Morphology & & & 0.581 & & & 0.671 \\
\hline Flat & $66(28.6)$ & $133(32.3)$ & & $116(36.4)$ & $201(34.9)$ & \\
\hline Subpedunculated & $118(51.1)$ & $195(47.3)$ & & $146(45.7)$ & $258(44.8)$ & \\
\hline Pedunculated & $47(20.3)$ & $84(20.4)$ & & $57(17.9)$ & $117(20.3)$ & \\
\hline Size & & & 0.000 & & & 0.001 \\
\hline$<0.5 \mathrm{~cm}$ & $9(3.9)$ & $39(9.5)$ & & $20(6.2)$ & $52(9.0)$ & \\
\hline $0.5-<1.0 \mathrm{~cm}$ & $76(32.9)$ & $193(46.8)$ & & $104(32.6)$ & $255(44.3)$ & \\
\hline $1.0-<2.0 \mathrm{~cm}$ & $112(48.5)$ & $151(36.7)$ & & $154(48.3)$ & $236(41.0)$ & \\
\hline$\geq 2.0 \mathrm{~cm}$ & $34(14.7)$ & $29(7.0)$ & & $41(12.9)$ & $33 \quad(5.7)$ & \\
\hline Pathological features & & & 0.000 & & & 0.014 \\
\hline Non-adenomas & $7(3.0)$ & $60(14.6)$ & & $16(5.0)$ & $62(10.8)$ & \\
\hline Non-advanced adenomas & $77(33.3)$ & $140(34.0)$ & & $104(32.6)$ & $180(31.3)$ & \\
\hline Advanced adenoma & $147(63.7)$ & $212(51.4)$ & & $199(62.4)$ & $334(58.0)$ & \\
\hline Advanced adenomas & & & 0.173 & & & 0.059 \\
\hline Size $\geq 1 \mathrm{~cm}$ & $108(73.5)$ & $150(70.8)$ & & $131(65.8)$ & $205(61.4)$ & \\
\hline$>25 \%$ Villous components & $32(21.8)$ & $58(27.4)$ & & $52(26.1)$ & $114(34.1)$ & \\
\hline High-grade intraepithelial neoplasia & $7 \quad(4.7)$ & $4(1.9)$ & & $16(8.0)$ & $15(4.5)$ & \\
\hline
\end{tabular}

revealed that the percentage of patients of normal weight with high-grade intraepithelial neoplasia was significantly higher in the NAFLD group (10.4\%) compared with the control group $(2.5 \%$; $\mathrm{P}>0.05)$, however, no statistically significant differences were observed in the obese patients between the NAFLD group and the controls as regards the percentage of advanced adenomas $(\mathrm{P}>0.05$; Table $\mathrm{V})$.

\section{Discussion}

Colorectal cancer is a common malignancy, ranking fourth among the causes of cancer-related mortality in China. Its incidence has increased in recent decades, and now more than one million Colorectal cancer patients are diagnosed and thousands succumb to the disease annually (7). The 5-year survival rate varies according to the stage at diagnosis, which is approximately $90 \%$ in the early stages of disease, and $<10 \%$ in advanced disease (8).

Colorectal polyps, particularly adenomatous polyps (including serrated adenomas), have been shown to be associated with the development of colorectal cancer. In addition to genetic factors, it has been found that colorectal cancer is closely associated with individual lifestyle and dietary habits, including physical activity, being overweight, cardiac obesity, a high-fat diet and smoking (9), which are also risk factors for the onset of NAFLD (10). In recent years, some studies have proposed a significantly association between NAFLD and the risk of developing colorectal adenoma (11-14).

It was previously demonstrated in a related study population that colorectal cancer patients with NAFLD had higher BMI and ALT values than colorectal cancer patients without NAFLD (11). Additionally, colorectal cancer patients with NAFLD were diagnosed earlier than colorectal cancer patients without NAFLD. However, no significant differences were observed between the 2 groups as regards the location and differentiation of tumors. The cumulative 1-, 3- and 5-year survival rates in colorectal cancer patients with NAFLD were 98.3, 89.8 and $86.4 \%$, respectively, which were higher, but statistically not significant than those of the CRC patients without NAFLD (90.4, 79.6 and $74.8 \%$, respectively). During the follow-up, freedom from recurrence was similarly observed in colorectal cancer patients with and without NAFLD. The results of that study suggest that the presence of NAFLD does not influence the prognosis of colorectal cancer patients; however, NAFLD is a risk factor for colorectal cancer and may be related with the development of colorectal polyps (11). Moreover, another retrospective study included data from 5,517 females, $15.1 \%$ of whom were diagnosed with NAFLD (12). During the follow-up, 
Table V. Comparison of features of polyps between the NAFLD and control groups according to BMI.

\begin{tabular}{|c|c|c|c|c|c|c|}
\hline \multirow[b]{2}{*}{ Parameter } & \multicolumn{3}{|c|}{ Normal weight $\left(\mathrm{BMI}<24 \mathrm{~kg} / \mathrm{m}^{2}\right)$} & \multicolumn{3}{|c|}{ Obese (overweight) $\left(\mathrm{BMI} \geq 24 \mathrm{~kg} / \mathrm{m}^{2}\right)$} \\
\hline & $\begin{array}{l}\text { NAFLD } \\
(\mathrm{n}=165)\end{array}$ & $\begin{array}{l}\text { Control } \\
(\mathrm{n}=592)\end{array}$ & P-value & $\begin{array}{l}\text { NAFLD } \\
(\mathrm{n}=385)\end{array}$ & $\begin{array}{l}\text { Control } \\
(\mathrm{n}=396)\end{array}$ & P-value \\
\hline Location & & & 0.422 & & & 0.719 \\
\hline Right colon & $16(9.7)$ & 69 (11.7) & & $40(10.4)$ & $42(10.6)$ & \\
\hline Left colon + rectum & $112(67.9)$ & $369(62.3)$ & & $218(56.6)$ & $234(59.1)$ & \\
\hline Colorectal & $37(22.4)$ & $154(26.0)$ & & $127(33.0)$ & $120(30.3)$ & \\
\hline Number of polyps & & & 0.920 & & & 0.082 \\
\hline Single & $52(31.5)$ & $189(31.9)$ & & $88(22.9)$ & $112(28.3)$ & \\
\hline Multiple & $113(68.5)$ & $403(68.1)$ & & $297(77.1)$ & $284(71.7)$ & \\
\hline Morphology & & & 0.423 & & & 0.653 \\
\hline Flat & 67 (40.6) & $210(35.5)$ & & $115(29.9)$ & $124(31.3)$ & \\
\hline Subpedunculated & $64(38.8)$ & $260(43.9)$ & & $200(51.9)$ & $193(48.7)$ & \\
\hline Pedunculated & 34 (20.6) & $122(20.6)$ & & $70(18.2)$ & $79(20.0)$ & \\
\hline Size & & & 0.000 & & & 0.001 \\
\hline$<0.5 \mathrm{~cm}$ & $9(5.5)$ & $59(10.0)$ & & $20 \quad(5.2)$ & $32(8.1)$ & \\
\hline $0.5-<1.0 \mathrm{~cm}$ & $45(27.3)$ & $279(47.1)$ & & $135(35.1)$ & $169(42.7)$ & \\
\hline $1.0-<2.0 \mathrm{~cm}$ & $90(54.5)$ & $218(36.8)$ & & $176(45.7)$ & $169(42.7)$ & \\
\hline$\geq 2.0 \mathrm{~cm}$ & $21(12.7)$ & $36(6.1)$ & & $54(14.0)$ & $26 \quad(6.5)$ & \\
\hline Pathological features & & & 0.001 & & & 0.001 \\
\hline Non-adenomas & $8 \quad(4.8)$ & $76(12.8)$ & & $15(3.9)$ & $46(11.6)$ & \\
\hline Non-advanced adenoma & $42(25.5)$ & $189(31.9)$ & & $139(36.1)$ & $131(33.1)$ & \\
\hline Advanced adenomas & $115(69.7)$ & $327(55.2)$ & & $231(60.0)$ & $219(55.3)$ & \\
\hline Advanced adenomas & & & 0.001 & & & 0.661 \\
\hline Size $\geq 1 \mathrm{~cm}$ & $77(67.0)$ & $210(64.2)$ & & $162(70.1)$ & $145(66.2)$ & \\
\hline$>25 \%$ Villous components & $26(22.6)$ & $109(33.3)$ & & $58(25.1)$ & $63(28.8)$ & \\
\hline High-grade intraepithelial neoplasia & $12(10.4)$ & $8 \quad(2.5)$ & & $11(4.8)$ & $11(5.0)$ & \\
\hline
\end{tabular}

the findings demonstrated a significant association between NAFLD and colorectal neoplasms. Among the various manifestations of metabolic syndrome, NAFLD may predict the development of colorectal neoplasms in women (12). Therefore, the study of the association between NAFLD and colorectal adenoma was conducive to the early screening and treatment of colorectal tumors.

In the present study, the personal and family tumor histories and other chronic intestinal diseases which affected the development of colorectal polyps were excluded; the revealed no statistically significant differences between the NAFLD group and the control group as regards the location and morphology of the polyps. However, the polyps in the patients with NAFLD tended to be multiple $(74.5 \%)$ compared with those in the non-NAFLD patients. Previous meta-analyses demonstrated that NAFLD was significantly associated with the number of colorectal adenomas $(13,14)$. Secondly, in the present study, the polyps in the patients with NAFLD were relatively larger in size, with $>60 \%$ of patients having polyps $\geq 1.0 \mathrm{~cm}$ in size, of which a polyp size of $\geq 2.0 \mathrm{~cm}$ accounted for $13.6 \%$ of the patients with NAFLD; however, in the control group, a polyp size of $\geq 2.0 \mathrm{~cm}$ only accounted for $6.3 \%$ of the patients. Therefore, endoscopists should pay attention to the characteristics of such patients. It is recommended that the patient's bowel preparation should be more adequate and attention should be paid to the parts that are easily missed during the examination, such as the back of the fold, the lengthy sigmoid colon, etc. Moreover, multiple and large polyps increase the difficulty of endoscopic treatment, and also require endoscopists to be vigilant to avoid surgical complications. As regards histopathology, the present study demonstrated that the percentage of advanced adenomas in the NAFLD group was higher than that of the control group (62.9 vs. 55.3\%). The study by Wong et al (15) demonstrated that in patients with NAFLD and colorectal tumors, the percentage of advanced adenomas was significantly higher than that of the non-NAFLD group. In addition, the study by Stadlmayr et al (16) demonstrated that the percentage of tubular adenomas was increased, although the percentage of advanced adenomas did not differ between the NAFLD group compared with the non-NAFLD group. Although the results of these studies slightly differ, the data of these studies indicate that the incidence of colorectal adenomas was significantly higher in NAFLD patients than in the general population. Therefore, attention should be paid to the characteristics of this class of patients with a high polyp histopathology, and early detection and timely treatment are of particular importance for these patients. As advanced adenomas become cancerous, patients will have to endure an increasing number of severe 
consequences, such as surgery and chemotherapy. At the same time, post-operative follow-up needs to emphasize the interval and number of examinations in order to avoid missed diagnosis and the recurrence of advanced adenoma. In terms of etiology, it may be related to the chronic inflammatory state and the abnormal hormone levels of NAFLD.

NAFLD is a type of acquired metabolic stress liver injury. Various changes in dietary intake which have occurred in recent years, characterized by an increase in energy intake due to enhancements in the consumption of flour, cereal products, added sugars and fats, and/or in total fat and fruit intake, are changes that have undoubtedly played a role in the increase in the prevalence of NAFLD in association with the increase in obesity. Consequently, the high prevalence of a high energy diet and obesity are closely associated with the incidence of colorectal tumors (17).

Some researchers have found that the serum levels of pro-inflammatory cytokines, such as including tumor necrosis factor (TNF)- $\alpha$, interleukin (IL)-6 and IL- 8 in patients with NAFLD are significantly higher than those in the normal population (18), which have been found to be significantly associated with the risk of developing colorectal cancer (19). These pro-inflammatory cytokines can stimulate cell growth, and induce the malignant transformation of cells by regulating the body's immunity. Therefore, these pro-inflammatory cytokines also regulate the progression of colorectal adenomas to colorectal cancerous. Similarly, the long-term use of drugs, such as aspirin or non-steroidal anti-inflammatory drugs (NSAIDs) may reduce the risk of colorectal cancer by inhibiting inflammatory responses (20). However, patients with NAFLD also exhibit an increase in hepatic oxidative stress and pro-lipogenic states. These are very important aspects as the decrease in the activity of the transcription factor, peroxisome proliferator-activated receptor (PPAR)- $\alpha$, allows for an increase in the pro-lipogenic and pro-inflammatory state in patients with NAFLD by the lower synthesis and/or deposits of n-3 polyunsaturated fatty acids (PUFAs). These are directly related to alterations in the regulation of cell reproduction to promote growth of colon polyps (21).

The levels of hormones are another important factor for the development of colorectal tumors in patients with NAFLD. For example, insulin resistance, as a risk factor for NAFLD, is closely related to colorectal adenoma and colorectal cancer (22). Increased levels of insulin regulate the number of liver growth hormone receptors to reduce insulin-like growth factor binding protein, upregulating insulin-like growth factor 1 (IGF-1), and subsequently inhibiting cell apoptosis through the IGF-1 signaling pathway, and thus promoting the malignant proliferation of cells (23). Adiponectin has been shown to be negatively associated with insulin resistance, and to play an anticancer role by inducing tumor cell apoptosis and inhibiting tumor angiogenesis (24). On the contrary, leptin play a promoting role in cancer, which is positively associated with insulin resistance, and promotes the proliferation, migration and invasion of tumor cells through various signaling pathways (25). Moreover, compared with the healthy population, the levels of adiponectin are decreased and the levels of leptin are increased in patients with NAFLD (26), both of which play important roles in the fat metabolic axis. Some studies $(27,28)$ have confirmed that adiponectin and leptin are involved into the occurrence of colorectal tumors.
The analysis of other data in the present study revealed that sex, age and being overweight only affected individual data as regards the association between NAFLD and colorectal polyps; however, a larger polyp size and the incidence of advanced adenomas in patients with NAFLD was more common compared with that in the control group. It should be noted that the proportion of high-grade intraepithelial neoplasia in patients with NAFLD with a normal weight was higher than that in the control group, the results of which will be further analyzed and discussed in future studies.

In conclusion, NAFLD has an impact on the development of colorectal polyps, which are characterized by a larger size, multiple polyps or the increasing incidence of advanced adenomas in affected patients. Therefore, clinical attention should be paid to the colonoscopy screening of patients with NAFLD. For patients with NAFLD with normal colonoscopy results, a change in their lifestyle and diet should be suggested, so as to prevent the occurrence of colorectal polyps.

\section{Acknowledgements}

Not applicable.

\section{Funding}

The present study was supported by the Health and Wellness Commission Fund of Jiading District (grant no. 2020-KY-15).

\section{Availability of data and materials}

The datasets used during the present study are available from the corresponding author upon reasonable request.

\section{Authors' contributions}

$\mathrm{XYu}, \mathrm{LX}$ and PC conceived and designed the study. YZ collected and assembled the data. XYuan and YW performed the data analysis and interpretation. All the authors contributed to the writing and final approval of the manuscript and agree to be accountable for all aspects of the research in ensuring that the accuracy or integrity of any part of the work are appropriately investigated and resolved.

\section{Ethics approval and consent to participate}

All the patients signed an informed consent form prior to the procedure. The informed consent forms obtained the consent of patients to use their clinical data, and they were assured that no identifiable personal information would be disclosed. The present study was approved by Ruijin Hospital North, Shanghai Jiaotong University School of Medicine (Shanghai, China) (approval no. 2017-2-01).

\section{Patient consent for publication}

Not applicable.

\section{Competing interests}

The authors declare that they have no competing interests. 


\section{References}

1. Safayeva AK and Bayramov NY: The importance of colonoscopy in the treatment of colorectal polyps and colorectal cancer screening. Ann Ital Chir 90: 311-317, 2019.

2. Byrne CD and Targher G: NAFLD: A multisystem disease. J Hepatol 62 (1 Suppl): S47-S64, 2015.

3. Hwang ST, Cho YK, Park JH, Kim HJ, Park DI, Sohn CI, Jeon WK, Kim BI, Won KH and Jin W: Relationship of non-alcoholic fatty liver disease to colorectal adenomatous polyps. J Gastroenterol Hepatol 25: 562-567, 2010.

4. Chitturi S, Farrell GC, Hashimoto E, Saibara T,Lau GK, Sollano JD Asia-Pacific Working Party on NAFLD: Non-alcoholic fatty liver disease in the Asia-Pacific region: Definitions and overview of proposed guidelines. J Gastroenterol Hepatol 22: 778-787, 2007.

5. Pan J, Wang M, Ye Z, Yu M, Shen Y, He Q, Cao N, Ning G, Bi Y, Gong W and Hu R: Optimal cut-off levels of obesity indices by different definitions of metabolic syndrome in a southeast rural Chinese population. J Diabetes Investig 7: 594-600, 2016.

6. IJspeert JE, Rana SA, Atkinson NS, van Herwaarden YJ, Bastiaansen BA, van Leerdam ME, Sanduleanu S, Bisseling TM, Spaander MC, Clark SK, et al: Clinical risk factors of colorectal cancer in patients with serrated polyposis syndrome: A multicentre cohort analysis. Gut 66: 278-284, 2017.

7. Zhu J, Tan Z, Hollis-Hansen K, Zhang Y, Yu C and Li Y: Epidemiological trends in colorectal cancer in China: An ecological study. Dig Dis Sci 62: 235-243, 2017.

8. Parizadeh SM, Parizadeh SA, Alizade-Noghani M, Jafarzadeh-Esfehani R, Ghandehari M, Mottaghi-Moghaddam A, Goldani F, Khazaei M, Ghayour-Mobarhan M, Ferns GA, et al: Association between non-alcoholic fatty liver disease and colorectal cancer. Expert Rev Gastroenterol Hepatol 13: 633-641, 2019.

9. Fu Z, Shrubsole MJ, Smalley WE, Wu H, Chen Z, Shyr Y, Ness RM and Zheng W: Lifestyle factors and their combined impact on the risk of colorectal polyps. Am J Epidemiol 176: 766-776, 2012

10. Leoni S, Tovoli F, Napoli L, Serio I, Ferri S and Bolondi L: Current guidelines for the management of non-alcoholic fatty liver disease: A systematic review with comparative analysis. World J Gastroenterol 24: 3361-3373, 2018.

11. Min YW, Yun HS, Chang WI, Kim JY, Kim YH, Son HJ, Kim JJ, Rhee JC and Chang DK: Influence of non-alcoholic fatty liver disease on the prognosis in patients with colorectal cancer. Clin Res Hepatol Gastroenterol 36: 78-83, 2012.

12. Lee YI, Lim YS and Park HS: Colorectal neoplasms in relation to non-alcoholic fatty liver disease in Korean women: A retrospective cohort study. J Gastroenterol Hepatol 27: 91-95, 2012.

13. Ding W, Fan J and Qin J: Association between nonalcoholic fatty liver disease and colorectal adenoma: A systematic review and meta-analysis. Int J Clin Exp Med 8: 322-333, 2015.

14. Shen H, Lipka S, Kumar A and Mustacchia P: Association between nonalcoholic fatty liver disease and colorectal adenoma: A systemic review and meta-analysis. J Gastrointest Oncol 5: 440-446, 2014.

15. Wong VW, Wong GL, Tsang SW, Fan T, Chu WC, Woo J, Chan AW, Choi PC, Chim AM, Lau JY, et al: High prevalence of colorectal neoplasm in patients with non-alcoholic steatohepatitis. Gut 60: 829-836, 2011.
16. Stadlmayr A, Aigner E, Steger B, Scharinger L, Lederer D, Mayr A, Strasser M, Brunner E, Heuberger A, Hohla F, et al: Nonalcoholic fatty liver disease: An independent risk factor for colorectal neoplasia. J Intern Med 270: 41-49, 2011.

17. Hernandez-Rodas MC, Valenzuela R and Videla LA: Relevant aspects of nutritional and dietary interventions in non-alcoholic fatty liver disease. Int J Mol Sci 16: 25168-25198, 2015.

18. Day CP: From fat to inflammation. Gastroenterology 130: 207-210, 2006.

19. Cui G, Yuan A, Goll R, Vonen B and Florholmen J: Dynamic changes of interleukin-8 network along the colorectal adenoma-carcinoma sequence. Cancer Immunol Immunother 58: 1897-1905, 2009.

20. Nolfo F, Rametta S, Marventano S, Grosso G, Mistretta A, Drago F, Gangi S, Basile F and Biondi A: Pharmacological and dietary prevention for colorectal cancer. BMC Surg 13 (Suppl 2): S16, 2013

21. Echeverría F, Ortiz M, Valenzuela R and Videla LA: Long-chain polyunsaturated fatty acids regulation of PPARs, signaling: Relationship to tissue development and aging. Prostaglandins Leukot Essent Fatty Acids 114: 28-34, 2016.

22. Keku TO, Lund PK, Galanko J, Simmons JG, Woosley JT and Sandler RS: Insulin resistance, apoptosis, and colorectal adenoma risk. Cancer Epidemiol Biomarkers Prev 14: 2076-2081, 2005.

23. Hang D, He X, Kværner AS, Chan AT, Wu K, Ogino S, Hu Z, Shen H, Pollak MN, Giovannucci EL and Song M: Plasma biomarkers of insulin and the insulin-like growth factor axis, and risk of colorectal adenoma and serrated polyp. JNCI Cancer Spectr 3: pkz056, 2019.

24. Kelesidis I, Kelesidis T and Mantzoros CS: Adiponectin and cancer: A systematic review. Br J Cancer 94: 1221-1225, 2006.

25. Jaffe $\mathrm{T}$ and Schwartz B: Leptin promotes motility and invasiveness in human colon cancer cells by activating multiple signal-transduction pathways. Int J Cancer 123: 2543-2556, 2008.

26. Li YL, Yang M, Meng XD, He XH and Wang BY: The relationship of leptin and adiponectin with insulin resistance in nonalcoholic fatty live disease. Zhonghua Gan Zang Bing Za Zhi 18: 459-462, 2010 (In Chinese).

27. Tilg $\mathrm{H}$ and Moschen AR: Mechanisms behind the link between obesity and gastrointestinal cancers. Best Pract Res Clin Gastroenterol 28: 599-610, 2014.

28. Wei EK, Giovannucci E, Fuchs CS, Willett WC and Mantzoros CS: Low plasma adiponectin levels and risk of colorectal cancer in men: A prospective study. J Natl Cancer Inst 97: 1688-1694, 2005.

This work is licensed under a Creative Commons Attribution-NonCommercial-NoDerivatives 4.0 International (CC BY-NC-ND 4.0) License. 